\title{
EL JUEZ DE GARANTÍA COMO ÓRGANO DE CONTROL DE LAS DISPOSICIONES DEL FISCAL DEL MINISTERIO PÚBLICO EN LA REFORMA PROCESAL PENAL
}

\author{
Marta Morales del Río \\ Profesora Derecho Administrativo \\ Universidad Católica del Norte, Coquimbo \\ INTRODUCCIÓN
}

La Reforma Procesal Penal, en los tiempos modernos (o posmodernos), pone en el tapete de la cuestión uno de los asuntos de mayor interés en la manera de entender la configuración del Estado de Derecho.

La redefinición estructural del modelo democrático en Chile, correlativamente demandó el paradigma de los derechos humanos como un principio fundamental de legitimidad, lo que conllevó aparejada una creciente exigencia de modernización de la Administración de Justicia, encaminada a fortalecer el Estado de Derecho ${ }^{1}$.

La misión principal de este tipo de Estado es la desconcentración de los poderes públicos, la cual se logra mediante una formalización y organización plena de controles, balances, pesos y contrapesos. Precisamente, uno de los objetivos fundamentales del sistema acusatorio es anular la confluencia en un mismo actor de las funciones de instrucción y juzgamiento, lo que indudablemente atentaba contra las exigencias del nuevo orden constitucional.

En el nuevo orden de cosas, se produce un desplazamiento significativo de funciones. En términos neurálgicos, se disocia la persecución penal pública del rol del juez, asignándosela a la figura del fiscal del Ministerio Público, que prácticamente pasa a monopolizar la investigación, desligándola del sujeto que juzga.

La reorganización orgánica del enjuiciamiento criminal plantea un sistema de control de la persecución penal pública en manos del Ministerio Público; surge la figura del Juez de Garantía, quien debe procurar un accionar garantístico, enderezado a la observancia del estatuto de garantías individuales consagrado en la Carta Fundamental.

En los nuevos estatutos, el Juez de Garantía tiene como misión primordial, a la luz de las normas constitucionales e internacionales de derechos humanos desde la perspectiva del debido proceso, esto es, aquéllas relevantes en cuanto a la regulación del procedimiento penal, proteger al imputado - quien se presume inocente - resolvien-

\footnotetext{
${ }^{1}$ Mensaje del Presidente de la República al proyecto de Código de Procedimiento Civil.
} 
do los conflictos que la actividad persecutoria del fiscal del Ministerio Público puedan generar en relación con sus derechos ${ }^{2}$.

Mi ponencia aborda la labor del juez de garantía, que está fundamentalmente encaminada a subordinar jurisdiccionalmente la investigación del Ministerio Público en cánones de legalidad y respeto a los imputados.

\section{I.- RECONOCIMIENTO POR LA LEY DE LA FACULTAD DE DISPOSICIÓN DEL FISCAL}

El proyecto de Reforma Procesal Penal introduce diversos mecanismos de selectividad orientados a racionalizar el procedimiento penal, que cabría encuadrar en la denominación genérica de "salidas alternativas" al proceso penal. Si bien parte de la doctrina estima que esta noción no comprende todo mecanismo destinado a descargar el sistema penal de los casos que conoce ${ }^{3}$, no cabe duda que las innovaciones que presenta el proyecto en orden a descomprimir el sistema penal, constituyen medios de solución alternativos de los conflictos sociales ${ }^{4}$.

Asimismo, es posible encuadrar dichos mecanismos en el denominado "Principio de Oportunidad", en sentido amplio, entendido como la capacidad legal del fiscal en disponer de la posibilidad de acusar o la facultad que asiste al titular de la acción penal para disponer, bajo determinadas condiciones, del ejercicio de ésta, con independencia que se haya acreditado la existencia de un hecho punible contra un autor determinado ${ }^{5}$.

A través de las señaladas herramientas procedimentales de iniciativa fiscal, que a continuación se tratan, el Ministerio Público ejercita actividades de disposición de la acción penal pública, propias del Sistema Acusatorio que se pretende implementar, en su carácter de detentador de dicha acción, mediante el ejercicio de un poder discrecional.

Como lo ha señalado Asencio Mellado, si bien el lus Puniendi pertenece al Estado, que ostenta el monopolio en materia de imposición de penas y en la ejecución de las mismas, el legislador puede sancionar fórmulas basadas en el Principio de Oportunidad que implican la atribución de caracteres diferenciados a los delitos públicos en función de criterios de lo más variado, como su banalidad, el interés de las víctimas, etc., intro-

2 İdem.

3 Según sostiene Mauricio Duce, un elemento que distingue a las salidas alternativas de otras válvulas de escape del sistema, es que éstas representan una "respuesta" menos represiva de parte del sistema a un determinado conflicto y no simplemente una decisión en el sentido de transparentar la imposibilidad del mismo de hacerse cargo de ese conflicto, ya sea por falta de medios probatorios que lo acrediten u otros motivos equivalentes. "Las Salidas Alternativas..." En Cuadernos de Análisis Jurídico № 39, Escuela de Derecho U. Diego Portales, pág. 234

4 DEL RÍO FERRETTI, Carlos y ROJAS RUBILAR, Francisco "De la Reforma Procesal Penal. En especial". Editorial Conosur, 1999, pág.399.

5 MARTINEz DALMAN, Rubén "Aspectos Constitucionales del Ministerio Fiscal", Editorial Universidad de Valencia, 1999, pág. 193 
duciendo mecanismos transaccionales en el proceso penal que de por sí implicarían una cierta disposición sobre el objeto por parte del acusador, cuanto de la defensa, teniendo como norte la consecución de otros fines, tales como la economía procesal, la minoración de los elevados costes procesales en asuntos de escasa importancia, la reparación de la víctima, etc... ${ }^{6}$

Los mecanismos de la señalada naturaleza a través de los cuales el fiscal dispone de la acción penal, regulados en el proyecto de Código de Procedimiento penal, son:

1) El Archivo Provisional de la Investigación.

2) El No inicio de la Investigación.

3) El Principio de Oportunidad

4) La Suspensión Condicional del Procedimiento

5) Los Acuerdos Reparatorios

6) El Procedimiento Abreviado

\section{II.- REGULACIÓN DE LAS SALIDAS ALTERNATIVAS Y SU CONTROL. EN ESPE- CIAL, EL CONTROL JUDICIAL}

\section{1.- Archivo Provisional}

El artículo 241 del proyecto, establece que el fiscal del Ministerio Público podrá archivar provisionalmente aquellas investigaciones en las que no aparecieren antecedentes que permitan desarrollar actividades conducentes al esclarecimiento de los hechos.

Control Interno: la víctima podrá solicitar del fiscal la reapertura del procedimiento y la realización de diligencias de investigación y podrá reclamar de la denegación de dicha solicitud ante las autoridades del Ministerio Público, según lo disponga la Ley Orgánica respectiva.

La ley № 19.640, Orgánica Constitucional del Ministerio Público, previene en sus artículos 32 b) y 33 , que corresponde al Fiscal Regional respectivo conocer y resolver, en el plazo de cinco días, las reclamaciones que formulen por escrito los intervinientes en un procedimiento en contra de un fiscal adjunto en conformidad a la ley procesal penal.

Se trata de un control interno jerárquico, a instancias de la víctima, que resguarda el poder del Ministerio Público en orden a descomprimir y racionalizar la persecución criminal, de acuerdo a las políticas fijadas por el Fiscal Nacional.

\footnotetext{
${ }^{6}$ ASENCIO MELLADO, José Maria "Principio Acusatorio y Derecho de Defensa", 1991, pág. 27-28
} 


\section{2.- Facultad para no iniciar investigación}

El artículo 242 del proyecto, previene que mediante resolución fundada, el fiscal podrá abstenerse de toda investigación, cuando los hechos relatados en la denuncia no fueren constitutivos de delito o cuando los antecedentes y datos suministrados permitan establecer que se encuentra extinguida la responsabilidad penal del imputado.

Este mecanismo me parece un interesante ejercicio de jurisdicción, ya que la facultad de declarar el derecho es propio de los Tribunales de Justicia, cuestión que resulta particularmente relevante en lo que concierne a la prescripción, materia esencialmente litigiosa y que por ende requiere un juicio y resolución judicial.

- Reglas comunes a las dos instituciones anteriores:

Oportunidad: en tanto no se hubiere producido la intervención del Juez de Control de la instrucción en el procedimiento (artículos 241 y 242).

En términos prácticos, esta oportunidad puede llegar a ser muy escasa, ya que las diligencias de instrucción que el fiscal puede realizar por sí solo, sin necesidad de requerir la autorización previa del Juez de Control - sin perjuicio de la investigación de antecedentes - se reducen a las actividades de vigilancia (artículo 284) y aquéllas practicadas con ocasión de los delitos flagrantes (artículo 277).

En efecto, las actuaciones de la instrucción que competen al Ministerio Público requieren, en su mayoría, decreto judicial previo. A guisa de ejemplo: La entrada y registro en lugares cerrados, artículo 276; la incautación de objetos sin existir orden previa de registro, artículos 255 y 289; el reconocimiento del imputado (vulgarmente conocida como rueda de presos), artículo 268; los exámenes corporales del imputado, artículo 273.

Control Judicial: a instancias de la víctima, mediante la interposición de la querella respectiva. Por el solo acto de admitir el juez a tramitación la querella, el Ministerio Público debe seguir adelante con la investigación conforme a las reglas generales.(artículo 243).

A través de este mecanismo, el control externo de las atribuciones del Ministerio Público se desplaza hacia la víctima, privilegiándose el carácter contradictorio del sistema en perjuicio del poder discrecional del fiscal, depositándose en la víctima la responsabilidad de la persecución criminal.

Tal como ha sido la intención del legislador, el ejercicio de los mecanismos referidos se encuentra delimitado por un preciso y estricto control, tanto judicial como interno o jerárquico (en el caso del archivo provisional) ${ }^{7}$, tan estricto, que en verdad reduce las posibilidades del fiscal al mínimo - considerando la breve oportunidad que,

${ }^{7}$ Mensaje del Presidente de la República al proyecto de Código..." Pág. 21. 
en la mayoría de los casos, tendría para actuar - constituyendo estas innovaciones sólo un tímido intento modernizador.

\section{3.- El Principio de Oportunidad .}

Mediante una decisión motivada, los fiscales del Ministerio Público podrán no iniciar la persecución penal o abandonar la ya iniciada cuando se tratare de un hecho que, por su insignificancia, no comprometiere gravemente el interés público, a menos que:

a) La pena mínima asignada al delito excediere la de presidio o reclusión menores en su grado mínimo (541 días), o bien

b) Se tratare de un delito cometido por un funcionario público en el ejercicio de sus funciones.

Control Judicial: El juez de garantía, de oficio o a petición de parte puede dejar sin efecto la decisión adoptada por el fiscal, cuando:

1) Éste se hubiere excedido de sus atribuciones.

Reviste interés precisar cuáles son las atribuciones del fiscal. Según lo previsto por la Ley № 19.640. Orgánica Constitucional del Ministerio Público, la función del Ministerio Público es dirigir en forma exclusiva la investigación de los hechos constitutivos de delito, los que determinen la participación punible y los que acrediten la inocencia del imputado y, en su caso, ejercer la acción penal pública en la forma prevista por la ley y adoptar las medidas para proteger a las víctimas y a los testigos.

Según lo previsto por el artículo 96 del proyecto de Código de Procedimiento Penal, en el ejercicio de su función de investigar, los fiscales cuentan con la atribución de realizar todas las actuaciones conducentes al éxito de la investigación. La extensión de esta potestad pública de obrar se encuentra delimitada por todas aquellas actuaciones que priven al imputado o a terceros del ejercicio de los derechos que la Constitución asegura, o los restrinjan o perturben, las que requieren autorización judicial previa.

En consecuencia, en el evento de ejecutar el fiscal alguna de tales actuaciones, sin la habilitación judicial pertinente, incurrirá en un vicio de abuso o exceso de poder, controlable por el Juez de Garantía.

2) La pena mínima prevista para el hecho de que se tratare excediere la de presidio o reclusión menores en su grado mínimo,

3) Se tratare de un delito cometido por un funcionario público en el ejercicio de sus funciones, 0

4) La víctima manifestare de cualquier modo su interés en el inicio o en la continuación de la persecución penal. 
Esta es una expresión del principio de promoción de los intereses concretos de las víctimas de los delitos ${ }^{8}$, consagrado en el artículo 95 del proyecto y en la ley Orgánica Constitucional del Ministerio Público. No se requiere que la víctima haya formalizado su actuación en el proceso penal mediante la deducción de la querella ni formalidad alguna en su manifestación de voluntad.

Control Interno: Una vez vencido el plazo (de diez días) desde la comunicación de la decisión del fiscal, o rechazada por el juez la reclamación respectiva, los intervinientes pueden impugnar la decisión del fiscal mediante reclamación ante las autoridades del Ministerio Público, según lo disponga la Ley Orgánica Constitucional respectiva. Este control se orienta a verificar si la aludida decisión se ajusta o no a las políticas generales del servicio y a las normas que hubieren sido dictadas al respecto.

Transcurrido dicho plazo sin que se hubiere formulado reclamación o rechazada ésta por parte de las autoridades del Ministerio Público, se entenderá extinguida la acción penal respecto del hecho de que se trate.

\section{4.- La Suspensión Condicional del Procedimiento}

Según la definición de Mauricio Duce, es una "salida alternativa al proceso en virtud de la cual se puede suspender condicionalmente el proceso o detener provisoriamente la persecución penal en favor de una persona imputada por un delito, quedando ella sometida, dentro de un determinado plazo, al cumplimiento de un conjunto de condiciones impuestas por el juez de control de la instrucción, al término del cual, si son cumplidas estas condiciones en forma satisfactoria, se extingue la acción penal y si, por el contrario, no lo son o se vuelve a imputar un nuevo delito, se revoca la medida iniciándose la persecución penal" 9 .

El artículo 311 del proyecto establece que para la procedencia de esta solución el fiscal debe obtener del imputado su acuerdo, el que conlleva la aceptación de los hechos materia de la persecución penal y de los antecedentes de la instrucción que la fundaren.

Control Judicial: El Juez de Garantía puede ejercitar el control jurisdiccional en dos etapas:

1) Control Previo. El Juez aprobará el referido acuerdo, oyendo a la víctima y al querellante, siempre que concurran los siguientes requisitos:

a) Si la pena privativa o restrictiva de la libertad que pudiera imponerse no excediere de tres años,

\footnotetext{
${ }^{8}$ Mensaje del Presidente de la República al proyecto de Código..." Pág. 16.

${ }^{9}$ En "Las Salidas Alternativas en el proyecto..." Cit. Nota 4.
} 
b) Si el imputado no ha sido condenado anteriormente por crimen o simple delito, $y$

c) Si los antecedentes personales del imputado, su conducta anterior y posterior al hecho punible y la naturaleza, modalidades y móviles determinantes del delito permiten presumir que no volverá a delinquir. (Estimo que este último requisito conduce a una antinomia carente de sentido, puesto que contraviene el principio de inocencia consagrado en el artículo 4 del proyecto, explicable por el origen de esta solución en las medidas alternativas reguladas por la Ley № 18.216).

d) No debe tratarse de los delitos de aborto, homicidio, secuestro, mutilación, lesiones gravísimas, violación, tráfico ilícito de estupefacientes y sustancias psicotrópicas y conductas terroristas.

e) Al conceder la suspensión condicional, el Juez debe establecer una o más de las condiciones - contempladas en el artículo 312 del proyecto - a las que deberá someterse el imputado dentro de un plazo judicial, que no podrá ser inferior a un año ni superior a tres.

1) Control posterior. Durante la vigencia de la suspensión condicional del procedimiento, el Juez de Garantía puede:

a) Modificar una o más de las condiciones impuestas, previo acuerdo del fiscal y del imputado.

b) Revocar la suspensión, en cuyo evento el caso deberá fallarse en conformidad con el Procedimiento Abreviado (artículo 466), si el imputado incumpliere grave, reiterada e injustificadamente las condiciones impuestas o fuere objeto de una nueva formalización de la instrucción por hechos distintos.

Además del control del Juez de Garantía, que puede ejercitar, no sólo a instancia de la víctima sino de oficio, la medida aceptada por éste puede ser objeto de un control jerárquico por la vía de la Apelación que puede interponer el querellante, lo cual significa que, en la práctica, la revisión posterior abarcará, no sólo la juridicidad de la solución adoptada, sino también el mérito o la conveniencia de su utilización ${ }^{10}$.

La normativa examinada revela que la facultad de disposición del fiscal se encuentra acotada dentro de límites de legalidad extremadamente estrechos, que aseguran la intromisión permanente de la judicatura, en beneficio del objetivo garantístico. Como ya se dijera a propósito del mecanismo referido al Principio de Oportunidad, son tan intensos los controles, que se convierten en respuestas muy precarias frente a los últimos desarrollos dogmático-procesales de países más avanzados o en otros países de nuestro continente en donde se han iniciado procesos de reforma similares al chileno ${ }^{11}$.

\footnotetext{
${ }^{10}$ En "Las Salidas Alternativas..." Idem nota 9

11 Idem a nota anterior.
} 


\section{5.- Los Acuerdos Reparatorios}

Constituyen una salida alternativa en virtud de la cual se puede extinguir la acción penal tratándose de cierta categoría de delitos, cuando exista entre la víctima y el imputado un acuerdo de reparación, prestado en forma libre y voluntaria, aprobado por el Juez de Control.

El artículo 315 del proyecto previene que esta solución procede cuando:

El delito que se persiga recayere sobre bienes jurídicos disponibles de carácter patrimonial o susceptibles de apreciación pecuniaria, esto es, básicamente delitos no violentos en contra de la propiedad ${ }^{12}, \mathrm{o}$

Se tratare de delitos culposos que no hubieren producido resultado de muerte ni afectaren en forma permanente y grave la integridad física de las personas.

Control Judicial: Corresponde al Juez de garantía aprobar el acuerdo, comprobando previamente que todos quienes hayan concurridoen él prestaron su consentimiento en forma libre y con pleno conocimiento de sus derechos.

Si bien esta solución no se regula explícitamente como de iniciativa fiscal, el Juez de Garantía deberá requerir su acuerdo, por cuanto al Ministerio Público le corresponde sostener la acción penal y en un Sistema Acusatorio, la disponibilidad del objeto del proceso pasa por la anuencia fiscal.

\section{6.- El Procedimiento Abreviado}

Es el mecanismo mediante el cual el imputado renuncia a su derecho al juicio oral, al manifestar su acuerdo en los hechos contenidos en la acusación y en los antecedentes de la instrucción que la fundan.

Según lo previsto por el artículo 467 del proyecto, cuando el fiscal requiriere la imposición de una pena no superior a cinco años de presidio o reclusión menores en su grado máximo o cualesquiera otras penas de distinta naturaleza, excepto la de muerte, ya fueren únicas, conjuntas o alternativas, puede proponer que la causa sea fallada en la audiencia de preparación del juicio oral.

Control Judicial: El acuerdo que presten el acusado y su defensor debe constar por escrito y ser ratificado ante el Juez de Garantía en la audiencia de preparación del juicio oral.

El Juez de Garantía puede ejercitar el control jurisdiccional previo:

a) De Oficio.

\footnotetext{
12 Idem a nota anterior.
} 
El artículo $\mathbf{4 7 0}$ del proyecto establece que antes de resolver sobre la solicitud del fiscal, el Juez de Garantía debe consultar al acusado a fin de asegurarse que éste ha prestado su conformidad al procedimiento abreviado en forma libre y voluntaria, de que conoce su derecho a exigir un juicio oral, que entiende los términos del acuerdo y las consecuencias que éste pueda significarle $y$, especialmente, que no ha sido objeto de coacciones ni presiones por parte del fiscal o de terceros.

b) A petición de parte.

Sólo el querellante puede oponerse al procedimiento abreviado cuando en su acusación particular hubiere efectuado una calificación jurídica de los hechos, atribuido una forma de participación o señalado circunstancias modificatorias de la responsabilidad penal diferentes de las consignadas por el fiscal en su acusación y, como consecuencia de ello, la pena solicitada excediere el límite señalado por el artículo 467.

Cuando el Juez, de oficio, estimare que el acuerdo no ha sido prestado por el acusado con conocimiento de sus derechos, libre y voluntariamente, o a petición de parte, considerare fundada la oposición del querellante, rechazará la solicitud de Procedimiento Abreviado y dictará el auto de apertura del juicio oral. En este caso, se tendrá por no formulada la aceptación de los hechos por parte del acusado ni la aceptación de los antecedentes de la instrucción que fundaren la acusación, como tampoco las modificaciones de la acusación o de la acusación particular efectuadas para posibilitar la tramitación abreviada del procedimiento.(artículo 471)

Además del control preventivo del Juez de Garantía, el acuerdo puede ser objeto de control jerárquico jurisdiccional por la Corte de Apelaciones respectiva, toda vez que la resolución del Juez de Garantía que acogiere la solicitud, es apelable (artículo $\mathbf{4 7 1}$ inciso final).

La normativa concerniente al acuerdo sobre Procedimiento Abreviado no escatima en controles. Así lo confiesa el propio legislador: "se ha preferido esta fórmula a aquélla en que se exige una aceptación explícita de culpabilidad, para permitir un control más intenso sobre los antecedentes del caso". ${ }^{13}$

En efecto, por tratarse de un mecanismo que coarta toda posibilidad de Juicio Oral, se privilegia el objetivo garantístico, evitándose el riesgo de infringir las garantías constitucionales.

\section{III.- NORMAS GENERALES SOBRE EL CONTROL JUDICIAL}

El proyecto de Código de Procedimiento Penal establece un conjunto de normas que configuran un sistema de control judicial previo a las actuaciones del fiscal del Ministerio Público o de habilitación previo decreto judicial.

\footnotetext{
${ }^{13}$ Mensaje del Presidente de la República al proyecto..." pág. 25.
} 
- El artículo 96 inciso $2^{0}$ del proyecto (contenido en las disposiciones generales, sobre los sujetos procesales) establece que "las actuaciones que priven al imputado o a terceros del ejercicio de los derechos que la constitución asegura, o los restrinjan o perturben, requerirán de aprobación judicial previa".

Esta norma se inserta precisamente en la disposición que consagra las atribuciones del fiscal, constituyéndose en la cota que define o enmarca dicha facultad (de llevar a cabo todas las actuaciones y diligencias conducentes al éxito de la investigación).

Artículo 267 (en el Título I del Libro Segundo, sobre la Etapa de Instrucción): Autorización Previa.

"Cuando alguna de las diligencias de investigación del fiscal del Ministerio Público pudieren privar al imputado o a terceros del ejercicio de los derechos que la Constitución les asegura, o los restrinjan o perturben, deberá solicitar la autorización del Juez de Control de la instrucción para practicarla". Agrega la norma que el Juez de Garantía debe velar por el cumplimiento de los requisitos previstos en cada caso.

Además, precisa que la resolución del Juez de Garantía que autorice la práctica de la diligencia debe ser fundada, expresando los motivos que la justifiquen.

El Juez de Garantía debe llevar a cabo este control a la luz de las disposiciones constitucionales que fijen las bases generales del ordenamiento jurídico y las que establecen los derechos y garantías individuales, y los tratados internacionales sobre derechos humanos ratificados por Chile, de conformidad a lo previsto por el artículo 9 del proyecto.

De las normas anotadas, es posible extraer las siguientes conclusiones:

1) Las actuaciones procesales del fiscal que incurran en la situación expresada en el inciso segundo del artículo 96, requieren de autorización judicial previa.

De no concurrir dicha habilitación, el Juez de Garantía debe decretar la Nulidad de Oficio, contemplada en los artículos 193 y 196 del proyecto, por cuanto surge la presunción de derecho de la existencia del perjuicio habilitante para la declaración de nulidad, si se hubiere impedido el pleno ejercicio de las garantías y de los derechos reconocidos en la Constitución, en los tratados internacionales ratificados por Chile y vigentes, o en las demás leyes de la República.

2) Se infiere entonces que las Salidas Alternativas de iniciativa fiscal, requieren siempre de autorización judicial previa, toda vez que, al constituir soluciones alternativas a la sentencia obtenida en Juicio Oral, garantía esencial del debido proceso, constituyen restricciones a las garantías constitucionales.

3) Con el objeto de llevar a cabo un control eficaz de las diligencias de instrucción en cada caso (artículo 267), el Juez de Garantía podría intervenir permanentemente en la gestión del fiscal, con el objeto de precaver la ocurren- 
cia de nulidades procesales, perjudicándose la investigación. Debe tenerse presente que desde la audiencia de preparación del juicio oral en adelante ya no pueden repetirse las diligencias o actuaciones de la instrucción (artículo 198), encontrándose en las manos del Juez de Garantía tanto la eficacia como las garantías de la investigación.

Al respecto, cabe considerar, asimismo, que la negligencia del Juez de Garantía en la debida protección del imputado será considerada como infracción a sus deberes, en conformidad a lo dispuesto por el artículo 342 del código Orgánico de Tribunales.

Según lo ya concluido por Rodrigo de la Barra, la reforma chilena apunta a una clara política de entrometimiento, debido principalmente a la cultura legal inquisitiva y a la introducción explícita del juez de control con facultades para revisar la mayoría de las decisiones del fiscal ${ }^{14}$.

Este Control preventivo le da al sistema un carácter inquisitivo y desperfila al ministerio Público como órgano de persecución independiente, simplemente le agrega un titular calificado en la legitimación para obrar contra el imputado de un hecho delictivo.

- Artículo 266: Sobre el Control Judicial anterior a la formalización de la instrucción.

"Cualquier persona que se considerare afectada por una investigación de un fiscal del Ministerio Público que no se hubiere formalizado judicialmente, podrá pedir al Juez de control de la instrucción que le ordene informar acerca de los hechos objeto de la investigación.

También podrá el juez fijarle un plazo para que formalice la acusación o cierre la investigación."

Me parece que, así como las garantías individuales conforman la cota máxima del ejercicio del poder del Ministerio Público, debieran serlo, asimismo, para el ejercicio de este derecho que se consagra a los ciudadanos afectados por una investigación fiscal. El Juez de Garantía debiera establecer, como standard de procedencia, la exigencia de haber sido amenazada o vulnerada alguna garantía constitucional.

\section{CONCLUSIONES}

No debemos hacer naufragar una experiencia que calará hondo en las instituciones procesales chilenas. Debemos comprender concienzudamente los términos del problema, los que se han ido depurando y/o problematizando en la práctica institucional del Derecho Comparado. Debemos entender la configuración difícil de independencia y control.

\footnotetext{
${ }^{14}$ DE LA BARRA, Rodrigo. En "Sistema Inquisitivo versus Adversarial...", 1999.
} 
El somero análisis de las nuevas normativas constitucionales y legales concernientes al Ministerio Público, nos permiten concluir, tentativamente, que dicha entidad no está plenamente habilitada para los efectos de alcanzar la eficiencia en la persecusión penal pública. Hago esa afirmación al tener a la vista el texto constitucional y legal que regula dicha entidad, el que prioritariamente subordina este ente al Poder Judicial, al punto de situarlo como un mero detentador de la acción penal, no dotándolo de los atributos discrecionales que deberían potenciar un quehacer institucional decididamente abocado a la plasmación del Sistema Acusatorio.

No se nos escapa la idea primordial del resguardo de las garantías individuales, que son el marco sustantivo de limitaciones de cualquier actuación estatal. Empero, si queremos configurar plenamente el proceso como jurisdiccional y no como un mero procedimiento administrativo, debemos poner en pie de igualdad a todos los agentes participantes, en la configuración procesal del ius puniendi estatal.

No nos engañemos. Si queremos realmente superar la institucionalidad del proceso inquisitivo, debemos adjudicar al Ministerio Público un ámbito de discrecionalidad genuina y más omnicomprensivo. Debemos alcanzar las máximas cotas de lo que constituye un proceso acusatorio, hablo en el sentido fuerte; se trata de reconocer las notas más ortodoxas del derecho procesal penal, que éste se ajuste a las pautas normativas: Una cosa es subordinar la actuación del Ministerio Público a los requerimientos constitucionales y legales; otra cosa es someterlo a las habilitaciones inhibidoras del Poder Judicial.

En estricto rigor, el Ministerio Público debería ser un órgano viable en la perspectiva de la independencia institucional, respecto de cualquier poder. Debería definirse en una independencia, no sólo orgánica, sino funcional.

\section{COMENTARIO FINAL}

La cuestión de modificar el Sistema Inquisitivo por un Sistema Acusatorio, entraña dificultades vertebrales. Se trata de perfiles de nuevas instituciones, en una referencialidad básica de racionalidad institucional, que no dé pie a mal entendidos inconsecuentes con la idea constitucional de poder público.

La reformulación radical de las estructuras de la administración de justicia que preconizan los nuevos estatutos legales, conllevan diversos posicionamientos y roles de los agentes involucrados (jueces, abogados, auxiliares de la administración de justicia).

La superación del sistema inquisitivo por un sistema acusatorio, pone en juego los requerimientos de una cultura legal que habrá de redefinir sus modos de operatividad y maneras de entender la persecución criminal y los diversos capítulos que ella contiene.

Pienso que la justificación de los cambios no puede ser puesta en tela de juicio, pero es obvio que la reforma del proceso penal enfrenta una serie de dificultades que, incluso, pueden ser calificadas de insalvables. 
Tengo la impresión que el proceso de reformas ha sido dirigido y promovido desde una instancia cupular o significativamente sectorial. Quiero decir que los márgenes de debate público han sido asociados a una propuesta apresurada o contingente, que no ha sido mediatizada por un alto compromiso académico y político de las diversas instancias institucionales involucradas. A guisa de ejemplo: hubo una ausencia de congresos interdisciplinarios donde participaran la mayoría de las universidades, no hubo debates televisivos en donde se congregaran los especialistas, las discusiones y sesiones legislativas, no se han publicado en libros o dossières de fácil acceso (como ejemplos concretos: el mensaje del Presidente de la República, o el Código Procesal Penal Modelo para Iberoamérica, de la mayor envergadura para comprender el proceso de reforma penal chileno, no fue distribuido en el curso de diplomado).

Se comprenderá entonces, que la reforma pueda abortar, al no estar presidida por un consenso verídico de todos los participantes.

Como una consecuencia de lo anterior, tengo la impresión de que los actores de una reforma drástica del sistema procesal chileno no entienden los verdaderos alcances de una proposición que compromete conductas, habilidades, y todo aquello que concierne a una forma de configurar una "cultura legal".

No se trata de corregir la arraigada cultura procesal inquisitiva por obra de "iluminados". Los cambios legales de la reforma procesal penal son sutiles y demandan la formación de una nueva burocracia, atenta al hondo dramatismo de las dificultades del proceso penal contemporáneo, lo cual no se logra por decreto ni por una mayor o menor condescendencia a las nuevas tendencias contemporáneas. Las nuevas estructuras, que pasan por una reestructuración amplia del Poder Judicial y/o Administración de Justicia, exigen una adecuación previa que reconozca la complejidad de los nuevos desafíos institucionales.

Los cambios revolucionarios del nuevo sistema deben respetar las exigencias de adhesión, asimilación y maduración del mismo. Reitero, la superación del Sistema Inquisitivo por un Sistema Acusatorio debe despertar el entusiasmo de todos los individuos asociados.

Todo lo anterior se hace más patente cuando la única referencia disponible es la cultura inquisitiva, por lo demás, profundamente arraigada en las prácticas forenses, donde se plasma la pretensión punitiva del Estado.

Me parece que estamos enfrentados a disyuntivas de difícil resolución; nada nos garantiza que todo el programa de reformas sea una cuestión meramente utópica. En la implementación real, podría sobrevenir la aparición de un sistema inquisitivo hipertrofiado, lo que nos conduciría a una frustración de marca mayor. Piénsese en la tremenda presión de los grupos políticos, por influir en las nuevas formas institucionales.

Excúsenme la expresión: "a río revuelto, ganancia de pescadores", lo que equivale a remitirse al viejo aforismo: "a perros viejos nuevos trucos". 
Me parece que el centro de preocupaciones debiera orientarse, no a una mayor o menor sofisticación de las leyes, sino a una formación ágil y a un reclutamiento de nuevos individuos, que no arrastren consigo la inercia de los antiguos comportamientos. Se trata de una nueva mentalidad. Ello, por cierto, requiere una fuerte motivación salarial y de capacitación, que induzca a los mejores a incorporarse a los nuevos cargos funcionarios.

No se trata de una pura intelectualidad mesiánica, dispuesta a poner todo en juego. La superación de los vicios del sistema inquisitivo nos debería conducir a la configuración de un nuevo estamento, dispuesto a la implementación de un sistema que se propone estandarizar con nuevos patrones la persecución y la garantía.

En suma, cuáles son las falencias que observo en las proposiciones reformistas:

a) Ausencia alarmante de análisis de Derecho Comparado; a los cursos que se están implementando no han asistido profesores de Estados Unidos e Italia que, con estudios y experiencia sostenida en dichos países, den cuenta de los resultados evolutivos o involutivos del Sistema Adversarial.

b) El contexto motivacional de tipo ideológico no se está verificando; cuando hablo de dicho contexto no me refiero a la generalizada percepción de que existen problemas en el enjuiciamiento criminal (izquierda: violación de derechos humanos; derecha: seguridad ciudadana), me refiero a los grados de adhesión a la reforma, a su ejecución concreta. Pareciera que los individuos de la práctica forense y de las agencias jurisdiccionales no están persuadidos de las bondades de los nuevos procedimientos y tampoco de su efectiva participación en las instituciones que se están poniendo en vigor.

Finalmente, la problemática del Ministerio Público nos conduce a una oscilación entre el escepticismo y el entusiasmo febril.

\section{BIBLIOGRAFÍA}

1. PROYECTO DE LEY: "CÓdIGO PROCESAL PENAL". (Actualizado al 15 de julio de 1999 por la Unidad Coordinadora de la Reforma Procesal Penal, Ministerio de Justicia de Chile).

2. LEY N 19.460 ORGÁNICA CONSTITUCIONAL DEL MINISTERIO PÚBLICO. Publicada el 15 de octubre de 1999.

3. MENSAJE. De S.E. El Presidente de la República con que se inicia el proyecto de ley que establece un nuevo Código de Procedimiento Penal. Junio de 1995.

4. AUtORES VARIOS. El Ministerio Público. Publicación basada en los trabajos publicados en la Revista de Ciencias Penales. Editorial Conosur, Santiago de Chile, 1995. 
5. ASENCIO MELLADO, José María. "Principio Acusatorio y Derecho de Defensa en el Proceso Penal". Editorial Trivium S.A., Madrid, 1991.

6. CAROCCA PEREZ, Alex. "El Ministerio Público en la historia y en el Derecho Comparado". Cuadernos de Análisis Jurídico, № 29, Escuela de Derecho de la Universidad Diego Portales, 1994.

7. CAROCCA PÉREZ, Alex. "Congruencia entre Acusación y Defensa en el nuevo Proceso Penal Chileno." Cuadernos de Análisis Jurídico, № 39, Escuela de Derecho de la Universidad Diego Portales.

8. DE LA BARRA COUSIÑO, Rodrigo. "La Reforma Procesal Penal en Chile: EI Ministerio Público, antecedentes y desafíos". Gaceta Jurídica. Asociación Nacional de Magistrados, Poder Judicial de Chile, febrero 1999.

9. DE LA BARRA COUSIÑO, Rodrigo. "La Reforma Procesal, el rol del juez, desafíos, perspectivas y propuestas para el mejoramiento." Gaceta Jurídica. Asociación Nacional de Magistrados, Poder Judicial de Chile, marzo 1999.

10. DE LA BARRA COUSIÑO, Rodrigo. "Sistema Inquisitivo versus Adversarial; cultura legal y perspectivas de la Reforma Procesal Penal en Chile." Santiago de Chile, abril 1999.

11. DEL RIO fERRETTI, Carlos; ROJAS RUBILAR, Francisco. "De la Reforma Procesal Penal. En especial de la etapa de Instrucción e Intermedia". Editorial Conosur Ltda., 1999, Santiago de Chile.

12. DUCE, Mauricio. "Las salidas alternativas en el proyecto de Reforma Procesal Penal (o al menos lo que queda de ellas)." Cuadernos de Análisis Jurídico, № 39 , Escuela de Derecho de la Universidad Diego Portales.

13. HORVITZ LENNON, María Inés. "Ministerio Público y selectividad". En Cuadernos de Análisis Jurídico. Escuela de Derecho, Universidad Diego Portales.

14. MARTÍNEZ DALMAU, Rubén. "Aspectos Constitucionales del Ministerio Fiscal", Tirant lo Blanch, Universidad de Valencia, 1999. 